\title{
BMJ Open Association between educational level and total and cause-specific mortality: a pooled analysis of over 694000 individuals in the Asia Cohort Consortium
}

\author{
Keming Yang, ${ }^{1}$ Ying Zhang, ${ }^{2}$ Eiko Saito, ${ }^{3}$ Md Shafiur Rahman, ${ }^{4}$ \\ Prakash Chandra Gupta, ${ }^{5}$ Norie Sawada, ${ }^{6}$ Akiko Tamakoshi, ${ }^{7}$ Yu-Tang Gao, ${ }^{8}$ \\ Woon-Puay Koh, ${ }^{9}$ Xiao-Ou Shu, ${ }^{10}$ Ichiro Tsuji, ${ }^{11}$ Atsuko Sadakane, ${ }^{12}$ \\ Chisato Nagata, ${ }^{13}$ San-Lin You, ${ }^{14}$ Jian-Min Yuan, ${ }^{15}$ Myung-Hee Shin, ${ }^{16}$ Yu Chen, ${ }^{17}$ \\ Wen-Harn Pan, ${ }^{18}$ Mangesh S Pednekar, ${ }^{5}$ Shoichiro Tsugane, ${ }^{6}$ Hui Cai, ${ }^{10}$ \\ Yong-Bing Xiang, ${ }^{8}$ Kotaro Ozasa, ${ }^{12}$ Yasutake Tomata, ${ }^{\oplus 11}$ Seiki Kanemura, ${ }^{11}$ \\ Yumi Sugawara, ${ }^{11}$ Keiko Wada, ${ }^{13}$ Renwei Wang, ${ }^{15}$ Yoon-Ok Ahn, ${ }^{19}$ \\ Keun-Young Yoo, ${ }^{20}$ Habibul Ahsan, ${ }^{21}$ Kee Seng Chia, ${ }^{22}$ Paolo Boffetta, ${ }^{23}$ \\ Daehee Kang, ${ }^{19}$ John D Potter, ${ }^{24}$ Manami Inoue, ${ }^{\circ 6}$ Wei Zheng, ${ }^{10}$ Hongmei Nan ${ }^{1}$
}

To cite: Yang K, Zhang Y, Saito $\mathrm{E}$, et al. Association between educational level and total and causespecific mortality: a pooled analysis of over 694000 individuals in the Asia Cohort Consortium. BMJ Open 2019;9:e026225. doi:10.1136/ bmjopen-2018-026225

- Prepublication history and additional material for this paper are available online. To view these files, please visit the journal online (http://dx.doi. org/10.1136/bmjopen-2018026225).

Received 22 August 2018 Revised 11 March 2019 Accepted 28 June 2019

A Check for updates

(c) Author(s) (or their employer(s)) 2019. Re-use permitted under CC BY-NC. No commercial re-use. See rights and permissions. Published by BMJ.

For numbered affiliations see end of article.

Correspondence to

Dr Hongmei Nan; hnan@iu.edu

\section{ABSTRACT}

Objective To study the association of educational level and risk of death from all causes, cardiovascular disease (CVD) and cancer among Asian populations.

Design A pooled analysis of 15 population-based cohort studies.

Setting and participants 694434 Asian individuals from 15 prospective cohorts within the Asia Cohort Consortium.

Interventions None.

Main outcome measures $\mathrm{HRs}$ and $95 \% \mathrm{Cls}$ for all-cause mortality, as well as for CVD-specific mortality and cancerspecific mortality.

Results A total of 694434 participants (mean age at baseline $=53.2$ years) were included in the analysis. During a mean follow-up period of 12.5 years, 103023 deaths were observed, among which 33939 were due to cancer and 34645 were due to CVD. Higher educational levels were significantly associated with lower risk of death from all causes compared with a low educational level (sprimary education); HRs and 95\% Cls for secondary education, trade/technical education and $\geq$ university education were 0.88 ( 0.85 to 0.92$), 0.81$ ( 0.73 to 0.90$)$ and $0.71(0.63$ to 0.80$)$, respectively $\left(p_{\text {trend }}=0.002\right)$. Similarly, HRs ( $95 \% \mathrm{Cls}$ ) were 0.93 (0.89 to 0.97$), 0.86$ (0.78 to 0.94 ) and 0.81 (0.73 to 0.89 ) for cancer death, and 0.88 (0.83 to 0.93 ), 0.77 (0.66 to 0.91 ) and 0.67 (0.58 to 0.77 ) for CVD death with increasing levels of education (both $\mathrm{p}_{\text {trend }}<0.01$ ). The pattern of the association among East Asians and South Asians was similar compared with sprimary education; $\mathrm{HR}(95 \% \mathrm{Cl})$ for all-cause mortality associated with $\geq$ university education was 0.72 (0.63 to 0.81) among 539724 East Asians (Chinese, Japanese and Korean) and 0.61 (0.54 to 0.69) among 154710 South Asians (Indians and Bangladeshis).

Conclusion Higher educational level was associated with substantially lower risk of death among Asian populations.

\section{Strengths and limitations of this study}

This is the first and largest $(n=694434)$ pooled analysis of Asians to evaluate the impact of educational level on mortality in Asia.

- Our study is a pooling project of 15 prospective cohort studies from multiple countries with long-term follow-up in the Asia Cohort Consortium (ACC).

- This analysis is based on high-quality individual data collected from participating cohorts and harmonised using a standardised process at ACC coordinating centre.

- Our study revealed an inverse association of educational levels and risk of death in Asian populations; in Asia, further studies examining the determinants of educational inequalities in mortality are warranted.

\section{INTRODUCTION}

Research has demonstrated that socioeconomic status (SES) has a significant impact on individual health status in terms of mortality, morbidity and disability. ${ }^{12}$ Educational attainment is closely related to income, occupation, access to medical care and lifestyle habits. As a major determinant of SES, education has been inversely associated with mortality, an overall measure of health. ${ }^{34}$

Several cohort analyses have examined the relationship between education and mortality in the Western countries. For example, an analysis of two large American Cancer Society cohorts followed from 1959 to 1996 showed that low educational level was associated with higher all-cause death rates. ${ }^{5}$ The follow-up of the US National Longitudinal Mortality Study 
(2002-2011) found that both all-cause and cause-specific mortalities were higher among the least-educated than among the most-educated groups, and educational disparities in mortality were more apparent in those aged 50-64 years than those aged 66-79 years. ${ }^{6}$ In the Europe, the inverse association between education with total and cause-specific mortality was also supported by a study of eight western European populations (19901997). ${ }^{7}$ Leinsalu et al examined the educational inequalities in mortality in four Eastern European countries (1990-2000); they found mortality rates decreased in similar patterns in all educational groups in Poland and Hungary, whereas in Estonia and Lithuania, mortality rates decreased among the highly educated group but increased among those with low education. Generally, over the past two decades, mortality has declined substantially in lower socioeconomic groups in most European countries; however, relative mortality inequalities widened because the declines were less marked in lower socioeconomic populations. ${ }^{9}$

In Asia, however, relatively few studies have assessed the education/mortality relationship among populations in this area. Further, such investigations were previously conducted only among one single country or area, such as South Korea, ${ }^{10}$ the city of Wuhan in China, ${ }^{11}$ Japan ${ }^{12}{ }^{13}$ and India. ${ }^{14}$ Based on the information from the UNESCO Institute for Statistics (http://data.uis.unesco. org), compared with European countries and the USA, mean years of schooling and higher education rates are relatively lower whereas disease and death burdens are relatively higher in Asian countries. ${ }^{15-17}$ Therefore, in this current study, we seek to examine the association of education and mortality in combined Asian populations by using pooled data from 15 prospective cohort studies in the Asia Cohort Consortium (ACC). The large sample size of this pooled analysis provided a strong statistical power to quantify the impact of educational levels on all-cause and major cause-specific mortalities in Asia.

\section{METHODS}

\section{Study population}

Our study is a pooling project of prospective cohort studies in the ACC, a collaborative effort committed to studying the aetiology of diseases in Asian populations.

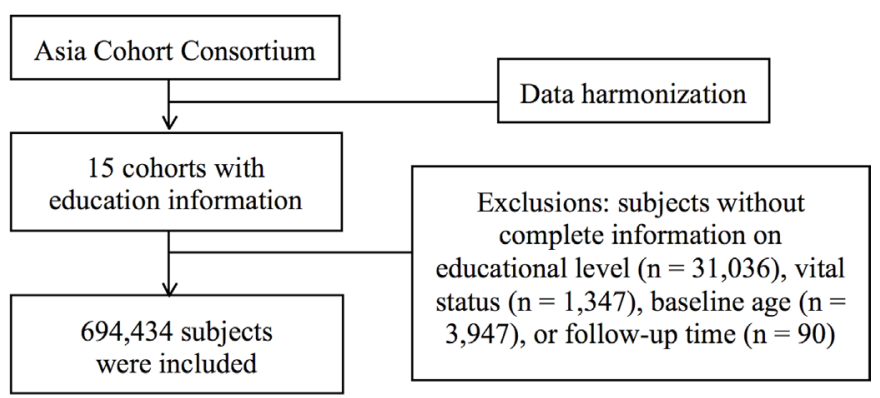

Figure 1 Flowchart of Asian individuals eligible for inclusion in the study.
The ACC includes more than 20 cohorts representing Japan, China, South Korea, India, Taiwan, Bangladesh and Singapore. Cohorts were identified through a systematic search of the literature in early 2008, followed by a survey sent to each cohort to assess data availability. Details of the ACC and each participating cohorts have been presented elsewhere. ${ }^{18}{ }^{19} \mathrm{~A}$ total of 15 cohorts had collected information about educational attainment and therefore have been included in this pooled analysis. Individual data from participating cohorts was collected and harmonised for the statistical analysis. This study was approved by the ethics committees of each individual cohort study and by the institutional review board of the ACC coordinating centre (Fred Hutchinson Cancer Research Center, Seattle, USA; National Cancer Center, Tokyo, Japan).

\section{Patient and public involvement}

Patients or public were not involved in this study.

\section{Data harmonisation}

Relevant data from each of the participating cohorts were transferred and harmonised at the ACC coordinating centre. Harmonisation involved several rounds of discussions to ensure that variables were correctly interpreted and extracted. Data were checked for illogical or missing values, and queries were sent back for clarification. The distributions of individual variables were explored to identify false or implausible values. All personal identifiers were removed, but study-specific ID numbers were retained to facilitate referral of all queries to the individual cohort.

\section{Education level and outcome measurements}

We excluded from our analysis participants without complete information on educational level $(\mathrm{n}=31036)$, vital status $(n=1347)$, baseline age $(n=3947)$ or follow-up time $(\mathrm{n}=90)$. After these exclusions, 694434 subjects from the 15 participating cohorts were included, among whom 539724 were East Asians (Chinese (including cohorts from mainland China, Taiwan, Singapore), Japanese and Koreans) and 154710 were South Asians (Indians and Bangladeshis). Among all included subjects, 344702 were men and 349732 were women (figure 1).

Information about completed education was collected by each cohort through questionnaire and harmonised into the following groups: Sprimary education (ie, no formal education or completed only primary education), secondary education (ie, high school education), technical/trade education (ie, associate degree) and $\geq$ university education (ie, undergraduate or graduate education). Data on all-cause and cause-specific mortality were ascertained through linkage to death certificate data or active follow-up. The diagnosis of cause-specific mortality was made according to the International Classification of Diseases, 9th or 10th Revision (ICD-9 or ICD-10): all cancer (ICD-9 codes: 140-208; ICD-10 codes: C00-C97), 
cardiovascular diseases (CVDs) (ICD-9 codes: 390-459; ICD-10 codes: I00-I99).

\section{Statistical analysis}

Cox proportional hazards regression models were utilised to estimate HRs and $95 \%$ CIs for the association between educational level and the risk of death, with ' $\leq$ primary education' as the reference group for the estimation. The ages of the subjects when they entered and exited the cohort were used to define the time scale in the Cox models. The entry time was defined as age at the baseline interview, and the exit time was defined as age at death or last follow-up, whichever occurred earlier.

We built up two models: the crude model, adjusted only for baseline age and gender; and the multivariable-adjusted model, which was further adjusted for other potential confounders, including residential location (urban, rural), marital status (single, married, widowed/separated/ divorced), body mass index (BMI) (underweight, normal, overweight, obese), smoking status (never, ever), alcohol drinking status (never, ever) and physical activity $(<1$ hour/ week, 1-2hours/week, 3-4hours/week, $\geq 5$ hours/ week). Cox models were performed for each cohort, and random-effects meta-analyses were conducted to summarise results across cohorts. In all models, the impact of educational level on the risk of death was assumed to be cohort-specific. ${ }^{20}$ We assumed that the log-HRs associated with education level had a fixed-effect component that was common to all cohorts within each country and a random effect that was cohort-specific. The random effects for log-HRs were assumed to be normally distributed, with mean zero; namely, we assumed that $\beta^{\prime} i j$, the estimated $\log$-HR for the $j$ th educational level in an $i$ th cohort, follows the distribution $\beta^{2} i j \sim N\left(\beta j, \hat{\sigma}^{2} i j+\hat{\tau}^{2} j\right)$, where $\hat{\sigma}^{2} i j$ is the within-study variance of $\beta^{\wedge} i j$ and $\hat{\tau}^{2} j$ is the between-cohort variance of $\beta i j$, as estimated from the Cox regression model. ${ }^{21} 22$

We also conducted stratified analyses by the covariates described above and assessed statistical significance of interaction using the Wald test for cross-product terms of covariates and education in the Cox models adjusted for other confounding factors. Cox model estimation for each cohort was performed using the PHREG procedure in SAS, V.9.4 (SAS Institute). The meta-analysis estimation was performed using STATA, V.14.0 (StataCorp LP). All tests were two-sided, and $p<0.05$ was considered statistically significant.

\section{RESULTS}

After exclusions, a total of 694434 participants were included in the 15 participating cohorts; half $(49.6 \%)$ were women. Nearly half $(50.2 \%)$ of study participants received no formal education or completed only primary education. Approximately $9 \%$ of study participants had received university or higher degrees at baseline. Our analysis included 103023 deaths during a mean follow-up period of 12.5 years, among which 33939 (33.0\%) were from cancer, $34645(33.6 \%)$ were from CVD and the remaining 34439
$(33.4 \%)$ were from other causes. Selected characteristics of cohorts included in the present study are listed in table 1.

We found inverse associations of education levels with all-cause mortality among our total population as well as populations from different countries or regions (table 2). When adjusted for age, sex, residential location, marital status, BMI, smoking, alcohol drinking status and physical activity, HRs for mortality were slightly attenuated compared with crude models (age- and sex-adjusted only), but remained statistically significant. No substantial difference was observed between the two models in terms of the pattern of the association. Among all combined cohorts, higher education level was significantly associated with lower risk of death from all causes; compared with $\leq$ primary education, multivariable-adjusted HRs and 95\% CIs for secondary education, trade/technical education and zuniversity education were 0.88 (0.85 to 0.92$), 0.81$ ( 0.73 to 0.90 ) and 0.71 (0.63 to 0.80$)$, respectively ( $\left.\mathrm{p}_{\text {trend }}=0.002\right)$. The pattern of association among East Asians and South Asians appeared similar; regarding all-cause mortality compared with $\leq$ primary education, multivariable-adjusted HRs and 95\% CIs for zuniversity education was 0.72 (0.63 to 0.81 ) among 539724 East Asians (Chinese, Japanese and Korean) and 0.61 (0.54 to 0.69) among 154710 South Asians (Indians and Bangladeshis).

A similar pattern of association was observed for cause-specific mortality due to CVD and cancer, while the strength of the inverse association was weaker for deaths due to cancer than those due to CVD and all causes (table 3). Compared with low educational level (ie, sprimary education), higher educational level was significantly associated with lower cancer-specific mortality (multivariable-adjusted HR $(95 \%$ CI) for secondary education $=0.93$ (0.89 to 0.97$)$, for trade/technical education $=0.86(0.78$ to 0.94$)$ and for zuniversity degree $=0.81$ ( 0.73 to 0.89$\left.), \mathrm{p}_{\text {trend }}=0.006\right)$, as well as lower CVD-specific mortality (multivariable-adjusted HR $(95 \% \mathrm{CI})$ for secondary education $=0.88$ (0.83 to 0.93$)$, for trade/technical education $=0.77$ (0.66 to 0.91 ) and for zuniversity degree $=0.67$ (0.58 to 0.77$\left.), \mathrm{p}_{\text {trend }}=0.002\right)$. As shown in table 3 , the significant gradient of the inverse association between education and cancer/CVD-specific mortality also appeared in the East Asian population-only analysis $(\mathrm{p}<0.05)$. In South Asians, compared with the reference group (ie, sprimary education), individuals with $\geq$ university education had significantly lower risk of death from CVD $(\mathrm{p}<0.05)$. The association between education and cancer-specific mortality was not statistically significant among South Asians probably due to the small numbers of deaths across different educational groups among South Asians.

We further examined the association between educational levels and risk of death due to all causes stratified by covariates (online supplementary table 1). We observed statistically significant effect modifications by age, gender, residential location, marital status, physical activity, smoking and alcohol consumption status on the association between education and all-cause mortality ( $p$ for interactions $<0.01)$. However, for all covariates except 


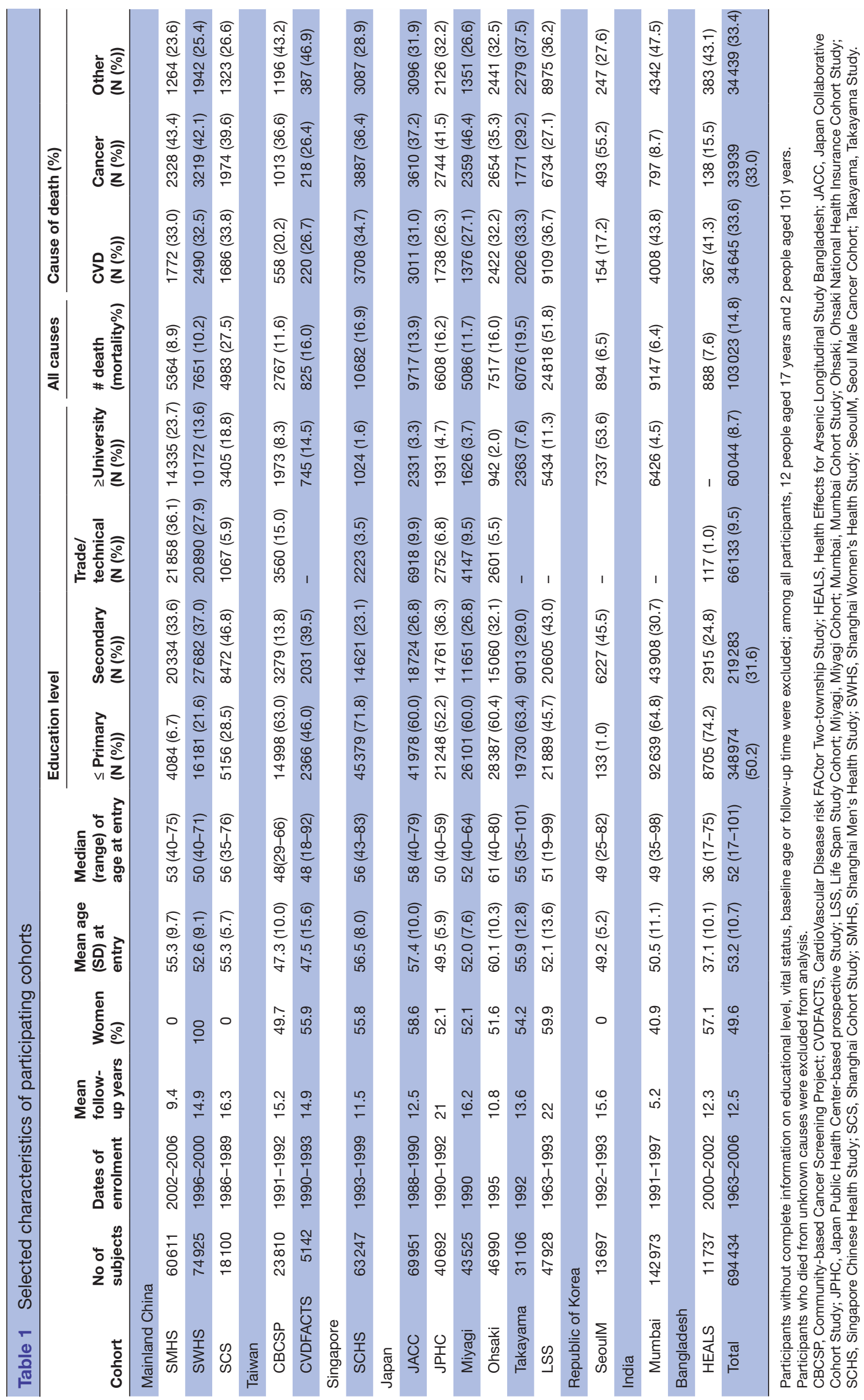


Table 2 Association of educational level with risk of death from all causes in selected study populations in Asia

\begin{tabular}{|c|c|c|c|c|}
\hline \multirow[b]{2}{*}{ Population } & \multicolumn{2}{|c|}{ Number } & \multirow{2}{*}{$\begin{array}{c}\text { Model } 1 \\
\text { HR }(95 \% \mathrm{Cl})\end{array}$} & \multirow{2}{*}{$\begin{array}{c}\text { Model } 2 \\
\text { HR }(95 \% \mathrm{Cl})\end{array}$} \\
\hline & Participants & Deaths & & \\
\hline \multicolumn{5}{|l|}{ All cohorts combined } \\
\hline$\leq$ Primary education & 348974 & 64948 & 1 & 1 \\
\hline Secondary education & 219283 & 26652 & $0.86(0.82$ to 0.90$)$ & 0.88 (0.85 to 0.92$)$ \\
\hline Trade/technical education & 66133 & 5195 & 0.76 (0.68 to 0.86$)$ & 0.81 (0.73 to 0.90$)$ \\
\hline$\geq$ University education & 60044 & 6228 & 0.66 (0.57 to 0.77 ) & 0.71 (0.63 to 0.80$)$ \\
\hline$P$ for trend & & & 0.002 & 0.002 \\
\hline \multicolumn{5}{|l|}{ Mainland China } \\
\hline$\leq$ Primary education & 25421 & 7227 & 1 & 1 \\
\hline Secondary education & 56488 & 5882 & 0.79 (0.76 to 0.83$)$ & $0.82(0.79$ to 0.85$)$ \\
\hline Trade/technical education & 43815 & 2702 & 0.64 (0.60 to 0.69$)$ & 0.69 (0.66 to 0.73$)$ \\
\hline$\geq$ University education & 27912 & 2187 & 0.50 (0.48 to 0.54$)$ & 0.56 (0.53 to 0.59$)$ \\
\hline $\mathrm{P}$ for trend & & & $<0.001$ & $<0.001$ \\
\hline \multicolumn{5}{|l|}{ Taiwan } \\
\hline$\leq$ Primary education & 17364 & 2777 & 1 & 1 \\
\hline Secondary education & 5310 & 478 & 0.83 (0.75 to 0.92$)$ & 0.85 (0.70 to 1.02$)$ \\
\hline Trade/technical education & 3560 & 202 & 0.75 (0.64 to 0.87 ) & $0.82(0.70$ to 0.95$)$ \\
\hline$\geq$ University education & 2718 & 135 & 0.50 (0.42 to 0.60$)$ & 0.57 (0.48 to 0.68$)$ \\
\hline $\mathrm{P}$ for trend & & & 0.03 & 0.08 \\
\hline \multicolumn{5}{|l|}{ Singapore } \\
\hline$\leq$ Primary education & 45379 & 8810 & 1 & 1 \\
\hline Secondary education & 14621 & 1596 & 0.76 (0.72 to 0.81$)$ & 0.81 (0.77 to 0.86$)$ \\
\hline Trade/technical education & 2223 & 205 & 0.67 (0.58 to 0.76$)$ & 0.75 (0.65 to 0.86$)$ \\
\hline$\geq$ University education & 1024 & 71 & 0.52 (0.41 to 0.66$)$ & 0.63 (0.50 to 0.80$)$ \\
\hline $\mathrm{P}$ for trend & & & 0.002 & 0.03 \\
\hline \multicolumn{5}{|l|}{ Japan } \\
\hline$\leq$ Primary education & 159333 & 38765 & 1 & 1 \\
\hline Secondary education & 89814 & 15833 & 0.92 (0.87 to 0.98$)$ & 0.94 (0.88 to 0.99$)$ \\
\hline Trade/technical education & 16418 & 2075 & 0.90 (0.81 to 1.00$)$ & 0.92 (0.82 to 1.02$)$ \\
\hline$\geq$ University education & 14627 & 3149 & 0.89 (0.80 to 0.99$)$ & 0.89 (0.80 to 0.99$)$ \\
\hline$P$ for trend & & & 0.47 & 0.36 \\
\hline \multicolumn{5}{|l|}{ Republic of Korea } \\
\hline$\leq$ Primary education & 133 & 17 & 1 & 1 \\
\hline Secondary education & 6227 & 480 & 0.75 (0.46 to 1.22$)$ & 0.77 (0.47 to 1.26$)$ \\
\hline Trade/technical education & - & - & - & - \\
\hline$\geq$ University education & 7337 & 397 & 0.48 (0.30 to 0.78$)$ & $0.52(0.32$ to 0.86$)$ \\
\hline$P$ for trend & & & $<0.001$ & $<0.001$ \\
\hline \multicolumn{5}{|l|}{ India } \\
\hline$\leq$ Primary education & 92639 & 6663 & 1 & 1 \\
\hline Secondary education & 43908 & 2195 & 0.83 (0.79 to 0.87 ) & 0.89 (0.85 to 0.94$)$ \\
\hline Trade/technical education & - & - & - & - \\
\hline$\geq$ University education & 6426 & 289 & 0.55 (0.48 to 0.61$)$ & 0.61 (0.54 to 0.69$)$ \\
\hline $\mathrm{P}$ for trend & & & $<0.001$ & $<0.001$ \\
\hline \multicolumn{5}{|l|}{ Bangladesh } \\
\hline$\leq$ Primary education & 8705 & 689 & 1 & 1 \\
\hline
\end{tabular}


Table 2 Continued

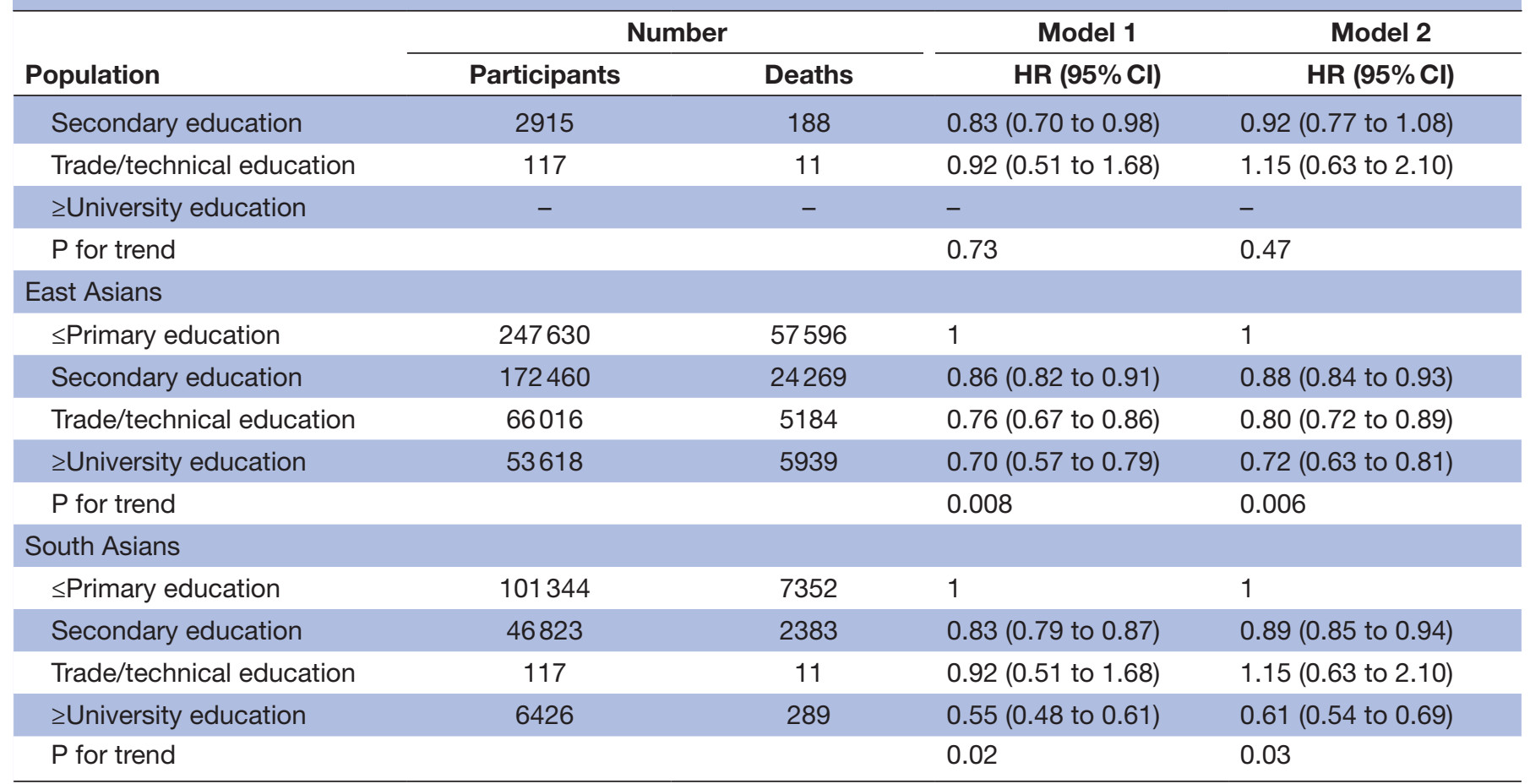

Model 1: adjust for baseline age and sex.

Model 2: adjust for baseline age, sex, urban/rural residence, marital status, body mass index, smoking status, alcohol consumption status and physical activity.

East Asians include participants from mainland China, Taiwan, Singapore, Republic of Korea and Japan; South Asians include participants from India and Bangladesh.

residential location and marital status, we did not find material differences among stratified groups in terms of the risk estimates of education on total mortality, although $p$ value for interaction was statistically significant.

\section{DISCUSSION}

In this large (694 434) pooled analysis of Asian populations, we found that higher educational level was associated with a substantially reduced risk of death from all causes, CVD and cancer. This inverse association presented a dose-response pattern. The mortality disparity did not appear to be explained solely by lifestyle factors such as the level of physical activity, smoking and alcohol consumption. Our study provides convincing evidence for the link between education and risk of death in Asian populations.

Our findings in Asian populations are generally similar to the results in studies carried out in Western countries. Kitagawa and Hauser, using 1960 US death records and census data, first examined the SES/mortality relationship. They found not only that both men and women with higher education have lower mortality rates and live longer than those with lower education but also that there is a significant gradient across the seven ordered categories of completed schooling. ${ }^{23}$ An additional 4years of education lowered 5 -year mortality by $1.8 \%$, according to the US National Bureau of Economic Research. ${ }^{24}$ A low level of education was also found to be associated with increased all-cause mortality compared with high levels of education in cohorts with type II diabetes ${ }^{25-27}$ and acute coronary syndrome. ${ }^{28}$ Recently, Mackenbach et al studied the trends in health inequalities in 27 European countries (1980-2014); they found that, in Western Europe, all-cause mortality has declined steadily in both low-educated and highly educated men and women; the trend in mortality was generally stable in both education groups. ${ }^{29}$ In Western Europe, absolute inequalities have usually decreased due to the larger absolute declines among the low-educated groups, but relative inequalities have generally increased because relative mortality declines were larger in the highly educated. ${ }^{29}$ However, since the 1990s, relative and absolute inequalities in mortality have both increased in Eastern Europe. ${ }^{89}$ The recent work by Mackenbach et al found that mortality has also begun to decline among the low-educated population in Eastern European countries; absolute inequalities in mortality have started to decrease as well. ${ }^{29}$

The inverse association between education and mortality was also found among older people in low-income and middle-income countries by a population-based cohort study of 12373 people aged $\geq 65$ years from Latin America, China and India. ${ }^{15}$ In 2014, Vathesatogkit et al performed and published the first meta-analysis of studies from Asia on the association between SES and mortality. ${ }^{30}$ Consistent with our findings, they found overall that those with the lowest level of education experienced a 1.4-fold higher risk 
Table 3 Association of educational level with risk of death from cardiovascular diseases and cancers in selected study populations in Asia

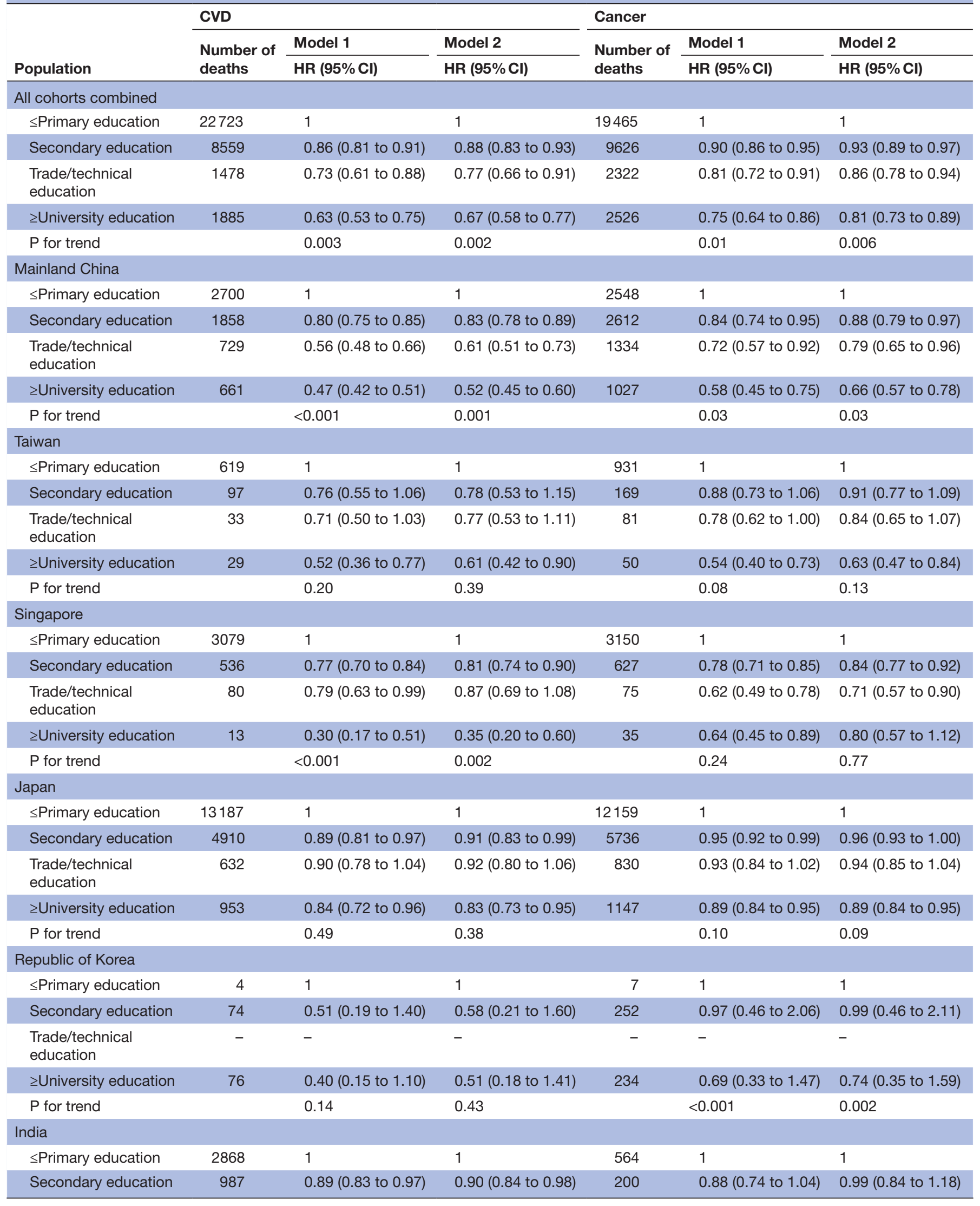

Continued 
Table 3 Continued

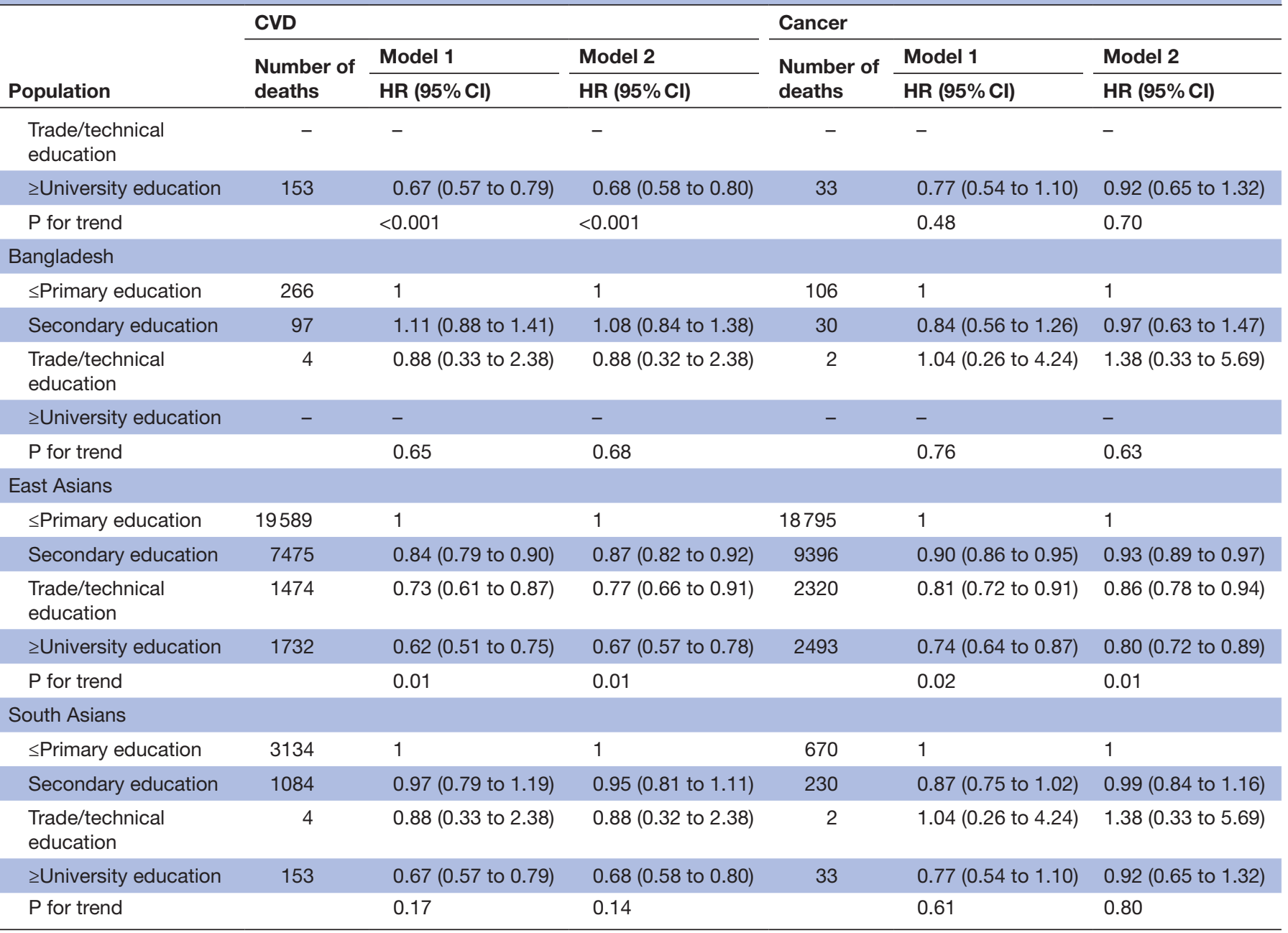

Model 1: adjust for baseline age and sex.

Model 2: adjust for baseline age, sex, urban/rural residence, marital status, body mass index, smoking status, alcohol consumption status and physical activity.

East Asians include participants from mainland China, Taiwan, Singapore, Republic of Korea and Japan; South Asians include participants from India and Bangladesh.

CVD, cardiovascular disease.

of mortality than the highest level of education (all cause: $\mathrm{RR}=1.41,95 \% \mathrm{CI}=1.29$ to 1.52 ; $\mathrm{CVD}: \mathrm{RR}=1.66,95 \% \mathrm{CI}=1.23$ to 2.25 ; cancer: $\mathrm{RR}=1.16,95 \% \mathrm{CI}=1.07$ to 1.27 ). However, we note that-unlike our pooled analysis-due to the nature of a meta-analysis based only on reported estimates from previous publications, the detailed educational levels in the comparison groups were not specified in the study by Vathesatogkit et $a l^{30}$

Educational attainment may not have a strong causal relationship with adult mortality. One nationwide quasi-experiment was conducted to examine the causal effect of education on mortality among 1.2 million Swedes; ${ }^{31}$ the exposure was a 1-year increase in compulsory schooling as an educational reform implemented in Sweden from 1949 to 1962 . No significant difference in all-cause mortality between the experimental and control groups was found during the entire follow-up ( $\mathrm{HR}=0.98,95 \% \mathrm{CI}=0.95$ to 1.01$)$ or among those aged $\leq 40$ years $(\mathrm{HR}=1.03,95 \% \mathrm{CI}=0.98$ to
1.07). Risk of death from all causes in the experimental group aged $>40$ years was lower than that in the control group with marginally significant association $(\mathrm{HR}=0.96$, 95\% CI $=0.93$ to 0.99$).{ }^{31}$ Interestingly, utilising a longitudinal dataset of Danish twins, Behrman et al found only weak evidence of an association between educational level and adult mortality among identical twin pairs who shared both the same genetic background and similar childhood social environments; but stronger evidence of the education/mortality relationship was found among fraternal twin pairs and unrelated individuals. ${ }^{32}$

Understanding the mechanisms by which educational attainment influences death risk is highly important for public policy making. There are several possible explanations. On one hand, education may affect health outcomes via people's SES (eg, occupation, income, wealth), social resources (eg, access to health information and healthcare services), health-related behaviours 
(eg, smoking, alcohol consumption, dietary habits, physical activity) and cognitive skills (eg, communication with physicians and nurses). On the other hand, a person's educational attainment can also act as a surrogate measurement for early-life factors such as parental SES, physical and mental health, childhood environment and social context ${ }^{43}$; in other words, education could lie on the pathway between those early-life factors and health outcomes (eg, mortality). Education seems to have an important latent effect on mortality into late life, suggesting that the adverse effect of low educational attainment and socioeconomic sequelae may accumulate across the life course. ${ }^{34}$

A study of 17 European countries (1970-2010) indicated that behavioural factors, including smoking and excessive alcohol consumption, were important contributors to the between-country variations in the magnitude of socioeconomic inequalities in mortality. ${ }^{35}$ By comparing estimates (ie, HRs) obtained from the crude model (age- and sexadjusted only) and the model further adjusted for each modifiable covariate individually, we found that smoking explained the most of the education-mortality association in our pooled data. Tobacco smoking is associated with a substantially increased risk of death among Asian adults, accounting for approximately 2 million deaths in adults aged over 45 years throughout Asia in 2004. ${ }^{18}$ Research has shown that smoking rates were higher among lower-educated people in many countries and the educational differences in smoking were more apparent in younger population than older generations. ${ }^{36-38}$ In our current study, the inverse associations between education and risk of death are significant in both never-smokers and ever-smokers; the magnitude of the association is slightly larger among those who never smoked (online supplementary table 1). In a study of 14 European countries, Gregoraci et al found that smoking-attributable mortality was inversely associated with socioeconomic levels defined by education and occupation in $2000-2004 .{ }^{39}$ Though the contribution of smoking to socioeconomic inequalities in mortality has been reduced since 1990-2004, smoking remains one of the most important intervention targets for reducing health equalities in Europe. ${ }^{39}$ In Asian populations, further studies examining the determinants of socioeconomic inequalities in mortality are warranted.

Our study has several strengths. First, this pooling project is the first and largest study evaluating the education/mortality relationship using combined Asian populations. Second, in contrast with a meta-analysis based on data from previous publications, our pooled analysis provides more accurate and reliable estimates by directly utilising individual data with standardised exposure measurement. Besides, the detailed covariate information collected in these cohorts enables a careful control for potential confounding and evaluation of effect modifications. We also acknowledge some limitations. First, because educational attainment data are self-reported at baseline in each cohort, we cannot rule out the possibility of misclassification. Additionally, there may be heterogeneity in education level across cohorts. However, we used a standardised harmonisation process on a range of environmental variables, including education level across 15 participating cohorts. Results presented in tables 2 and 3 show the consistency of the association between educational level and risk of death on a per-study level, and the pooled risk estimate is similar to that found in prior studies. ${ }^{527}$ Thus, bias due to self-report and heterogeneity in educational level is likely to be minimal. Second, we also cannot completely rule out the possibility that some participants might have had further education during follow-up after baseline enrolment (mean age at baseline $=53.2$ years). However, in Asian countries, pursuit of further education among older adults is not as popular as in Western countries. Thus, such missing information seems less likely to affect our findings.

\section{CONCLUSION}

Despite the limitations mentioned above, our study provides the best estimate of the impact of education on all-cause as well as major cause-specific mortality in Asian populations to date. Our findings may contribute to better public policy decisions, especially regarding increasing educational opportunities for Asian populations as a powerful intervention to reduce both morbidity and mortality.

\section{Author affiliations}

${ }^{1}$ Department of Epidemiology, Richard M. Fairbanks School of Public Health, Indiana University, Indianapolis, Indiana, USA

${ }^{2}$ Department of Biostatistics, College of Public Health, University of Nebraska

Medical Center, Omaha, Nebraska, USA

${ }^{3}$ Division of Cancer Statistics Integration, Center for Cancer Control and Information Services, National Cancer Center, Tokyo, Japan

${ }^{4}$ Department of Global Health Policy, Graduate School of Medicine, The University of Tokyo, Tokyo, Japan

${ }^{5}$ Healis - Sekhsaria Institute for Public Health, Navi Mumbai, India

${ }^{6}$ Epidemiology and Prevention Group, Center for Public Health Sciences, National

Cancer Center, Tokyo, Japan

${ }^{7}$ Faculty of Medicine, Hokkaido University, Sapporo, , Japan

${ }^{8}$ State Key Laboratory of Oncogene and Related Genes \& Department of Epidemiology, Shanghai Cancer Institute, Renji Hospital, Shanghai Jiaotong University School of Medicine, Shanghai, China

${ }^{9}$ Health Services and Systems Research, Duke-NUS Medical School, Singapore

${ }^{10}$ Division of Epidemiology, Department of Medicine, Vanderbilt Epidemiology Center, Vanderbilt-Ingram Cancer Center, Vanderbilt University Medical Center, Nashville,

Tennessee, USA

${ }^{11}$ Tohoku University Graduate School of Medicine, Sendai, Japan

${ }^{12}$ Department of Epidemiology, Radiation Effects Research Foundation, Hiroshima, Japan

${ }^{13}$ Department of Epidemiology and Preventive Medicine, Gifu University Graduate School of Medicine, Gifu, Japan

${ }^{14}$ School of Medicine, Big Data Research Centre, Fu-Jen Catholic University, Taipei, Taiwan

${ }^{15}$ Division of Cancer Control and Population Sciences, UPMC Hillman Cancer Center, University of Pittsburgh, Pittsburgh, Pennsylvania, USA

${ }^{16}$ Department of Social and Preventive Medicine, Sungkyunkwan University School of Medicine, Seoul, The Republic of Korea

${ }^{17}$ Department of Population Health, Department of Environmental Medicine, New

York University School of Medicine, New York City, New York, USA

${ }^{18}$ Institute of Biomedical Sciences, Academia Sinica, Taipei, Taiwan

${ }^{19}$ Department of Preventive Medicine, Seoul National University College of Medicine, Seoul, The Republic of Korea 
${ }^{20}$ Armed Forces Capital Hospital, Seoul National University College of Medicine, Seoul, The Republic of Korea

${ }^{21}$ Department of Public Health Sciences, The University of Chicago, Chicago, Illinois, USA

${ }^{22}$ Epidemiology Program, Saw Swee Hock School of Public Health, National University of Singapore, Singapore

${ }^{23}$ Icahn School of Medicine at Mount Sinai, New York, New York, USA

${ }^{24}$ Centre for Public Health Research, Massey University, Wellington, New Zealand

Acknowledgements The authors would like to thank all research team members and participants of each cohort study for their contribution to this research.

Contributors HN was responsible for the study concept and design. PCG, NS, AT, Y-TG, W-PK, X-OS, IT, AS, CN, S-LY, J-MY, M-HS, YC, W-HP, MSP, ST, HC, Y-BX, KO, YT, SK, YS, KW, RW, Y-OA, K-YY, HA, KSC, PB, DK, JDP, MI and WZ were involved in data collection and contributed to study materials. ES and MSR were involved in data management. $K Y$ analyzed the data and drafted the manuscript. All authors $(K Y, Y Z$, ES, MSR, PCG, NS, AT, Y-TG, W-PK, X-OS, IT, AS, CN, S-LY, J-MY, M-HS, YC, W-HP, MSP, ST, HC, Y-BX, KO, YT, SK, YS, KW, RW, Y-OA, K-YY, HA, KSC, PB, DK, JDP, MI, WZ, $\mathrm{HN}$ ) contributed to the interpretation of the results and revision of the manuscript critically for important intellectual content. KY and $\mathrm{HN}$ are guarantors. All authors, external and internal, had full access to all of the data (including statistical reports and tables) in the study and can take responsibility for the integrity of the data and the accuracy of the data analysis.

Funding There is no funding for this specific analysis. The cohorts participating in the pooled analysis were supported by the following grants: Japan Public Health Center-based prospective Study (JPHC Study), National Cancer Center Research and Development Fund (23-A-31(toku) and 26-A-2) (since 2011) and a Grant-in-Aid for Cancer Research from the Ministry of Health, Labour and Welfare of Japan (from 1989 to 2010); Japan Collaborative Cohort Study (JACC), National Cancer Center Research and Development Fund, A Grant-in-Aid for Cancer Research; Grant for Health Services and Grant for Comprehensive Research on Cardiovascular and Life-Style Related Diseases from the Ministry of Health, Labour and Welfare, Japan; Grant for the Scientific Research from the Ministry of Education, Culture, Sports, Science and Technology, Japan; Shanghai Women's Health Study (SWHS), the US National Cancer Institute (grant numbers R37 CA070867 and UM1 CA182910); Singapore Chinese Health Study (SCHS), National Institutes of Health (R01CA144034, UM1CA182876); Shanghai Men's Health Study (SMHS), the US National Cancer Institute (R01 CA082729 and UM1 CA173640); Shanghai Cohort Study (SCS), National Institutes of Health (R01CA144034, UM1CA182876); Ohsaki National Health Insurance Cohort Study, Grants-in-Aid for Cancer Research and for the Third Term Comprehensive Ten-Year Strategy for Cancer Control (H21-3jiganippan-003), Ministry of Health, Labour and Welfare; Miyagi Cohort, Grants-in-Aid for Cancer Research and for the Third Term Comprehensive Ten-Year Strategy for Cancer Control (H21-3jigan-ippan-003), Ministry of Health, Labour and Welfare; Life Span Study Cohort, The Japanese Ministry of Health, Labour and Welfare and the US Department of Energy; Takayama Study, National Cancer Center Research and Development Fund; CardioVascular Disease risk FACtor Two-township Study (CVDFACTS), Department of Health, Taiwan (DOH80-27, DOH81-021, DOH8202-1027, DOH83-TD-015 and DOH84-TD-006); Community-Based Cancer Screening Program (CBCSP), National Science Council and Department of Health, Taiwan; Seoul Male Cancer Cohort, National R\&D Program for Cancer Control, Ministry of Health and Welfare, Republic of Korea (0520160-1); Health Effects of Arsenic Longitudinal Study (HEALS), National Institutes of Health (P42ES010349, R01CA102484, R01CA107431); Mumbai Cohort Study, International Agency for Research on Cancer, Lyon, France; Clinical Trials Service Unit, Oxford, UK; World Health Organisation, Geneva, Switzerland. The funders had no role in the study design, data collection and analysis, decision to publish or preparation of the manuscript.

Competing interests None declared.

Patient consent for publication Not required.

Ethics approval This study was approved by the ethics committees of each individual cohort study and by the institutional review board of the ACC coordinating center (Fred Hutchinson Cancer Research Center, Seattle, USA; National Cancer Center, Tokyo, Japan).

Provenance and peer review Not commissioned; externally peer reviewed.

Data availability statement The datasets analysed during the current study (deidentified participant data) are available from the corresponding author upon reasonable request.
Open access This is an open access article distributed in accordance with the Creative Commons Attribution Non Commercial (CC BY-NC 4.0) license, which permits others to distribute, remix, adapt, build upon this work non-commercially, and license their derivative works on different terms, provided the original work is properly cited, appropriate credit is given, any changes made indicated, and the use is non-commercial. See: http://creativecommons.org/licenses/by-nc/4.0/.

\section{REFERENCES}

1. Adler NE, Newman K. Socioeconomic disparities in health: pathways and policies. Health Aff 2002;21:60-76.

2. Mackenbach JP, Stirbu I, Roskam A-JR, et al. Socioeconomic inequalities in health in 22 European countries. N Engl $\mathrm{J}$ Med Overseas Ed 2008;358:2468-81.

3. Samir KC, Lentzner H. The effect of education on adult mortality and disability: a global perspective Vienna Yearbook of Population Research; 2010: 201-35.

4. Hummer RA, Hernandez EM. The effect of educational attainment on adult mortality in the United States. Popul Bull 2013;68:1-16.

5. Steenland K, Henley J, Thun M. All-Cause and cause-specific death rates by educational status for two million people in two American cancer Society cohorts, 1959-1996. Am J Epidemiol 2002;156:11-21.

6. Ma J, Altekruse $\mathrm{S}$, Cosgrove $\mathrm{C}$, et al. Educational disparities in mortality between adults aged 50-64 and 66-79 years, U.S. Am J Prev Med 2017;52:728-34.

7. Huisman M, Kunst AE, Bopp M, et al. Educational inequalities in cause-specific mortality in middle-aged and older men and women in eight Western European populations. The Lancet 2005;365:493-500.

8. Leinsalu M, Stirbu I, Vågerö D, et al. Educational inequalities in mortality in four eastern European countries: divergence in trends during the post-communist transition from 1990 to 2000. Int J Epidemiol 2009;38:512-25.

9. Mackenbach JP, Kulhánová I, Artnik B, et al. Changes in mortality inequalities over two decades: register based study of European countries. BMJ 2016;353.

10. Khang Y-H, Lynch JW, Kaplan GA. Health inequalities in Korea: ageand sex-specific educational differences in the 10 leading causes of death. Int J Epidemiol 2004;33:299-308.

11. Liang J, McCarthy JF, Jain A, et al. Socioeconomic gradient in old age mortality in Wuhan, China. J Gerontol B Psychol Sci Soc Sci 2000;55:S222-S233.

12. Fujino $\mathrm{Y}$, Tamakoshi $\mathrm{A}$, Iso $\mathrm{H}$, et al. A nationwide cohort study of educational background and major causes of death among the elderly population in Japan. Prev Med 2005;40:444-51.

13. Ito S, Takachi R, Inoue M, et al. Education in relation to incidence of and mortality from cancer and cardiovascular disease in Japan. Eur $J$ Public Health 2008;18:466-72.

14. Pednekar MS, Gupta R, Gupta PC. Illiteracy, low educational status, and cardiovascular mortality in India. BMC Public Health 2011;11:567.

15. Ferri CP, Acosta D, Guerra M, et al. Socioeconomic factors and all cause and cause-specific mortality among older people in Latin America, India, and China: a population-based cohort study. PLoS Med 2012;9:e1001179.

16. UNESCO. The UNESCO Institute for statistics. Available: http://data. uis.unesco.org [Accessed 15 Feb 2019].

17. Ryan CL, Bauman K. Educational attainment in the United States: 2015. U.S. census bureau. Available: https://www.census.gov/ content/dam/Census/library/publications/2016/demo/p20-578.pdf [Accessed 22 Feb 2019].

18. Zheng W, McLerran DF, Rolland BA, et al. Burden of total and cause-specific mortality related to tobacco smoking among adults aged $\geq 45$ years in Asia: a pooled analysis of 21 cohorts. PLoS Med 2014;11:e1001631.

19. Zheng W, McLerran DF, Rolland B, et al. Association between bodymass index and risk of death in more than 1 million Asians. N Engl J Med 2011;364:719-29.

20. Smith CT, Williamson PR, Marson AG. An overview of methods and empirical comparison of aggregate data and individual patient data results for investigating heterogeneity in meta-analysis of time-toevent outcomes. J Eval Clin Pract 2005;11:468-78.

21. Brockwell SE, Gordon IR. A comparison of statistical methods for meta-analysis. Stat Med 2001;20:825-40.

22. DerSimonian R, Laird N. Meta-Analysis in clinical trials. Control Clin Trials 1986;7:177-88.

23. Kitagawa EM, Hauser PM. Differential mortality in the United States: a study in socioeconomic epidemiology. Cambridge, Massachusetts: Harvard University Press, 1973. 
24. National Bureau of Economic Research. The effects of education on health. Available: http://www.nber.org/digest/mar07/w12352.htm [Accessed 8 Aug 2017].

25. Blomster Jl, Zoungas S, Woodward M, et al. The impact of level of education on vascular events and mortality in patients with type 2 diabetes mellitus: results from the advance study. Diabetes Res Clin Pract 2017;127:212-7.

26. Saydah SH, Imperatore G, Beckles GL. Socioeconomic status and mortality: contribution of health care access and psychological distress among U.S. adults with diagnosed diabetes. Diabetes Care 2013;36:49-55.

27. Rawshani A, Svensson A-M, Zethelius B, et al. Association between socioeconomic status and mortality, cardiovascular disease, and cancer in patients with type 2 diabetes. JAMA Intern Med 2016:176:1146-54

28. Notara V, Panagiotakos DB, Kogias Y, et al. The impact of educational status on 10-year (2004-2014) cardiovascular disease prognosis and all-cause mortality among acute coronary syndrome patients in the Greek acute coronary syndrome (GREECS) longitudinal study. J Prev Med Public Health 2016;49:220-9.

29. Mackenbach JP, Valverde JR, Artnik B, et al. Trends in health inequalities in 27 European countries. Proc Natl Acad Sci U S A 2018;115:6440-5.

30. Vathesatogkit P, Batty GD, Woodward M. Socioeconomic disadvantage and disease-specific mortality in Asia: systematic review with meta-analysis of population-based cohort studies. $J$ Epidemiol Community Health 2014;68:375-83.
31. Lager ACJ, Torssander J. Causal effect of education on mortality in a quasi-experiment on 1.2 million Swedes. Proc Natl Acad Sci U S A 2012;109:8461-6.

32. Behrman JR, Kohler H-P, Jensen VM, et al. Does more schooling reduce hospitalization and delay mortality? new evidence based on Danish twins. Demography 2011;48:1347-75.

33. Hayward MD, Hummer RA, Sasson I. Trends and group differences in the association between educational attainment and U.S. adult mortality: implications for understanding education's causal influence. Soc Sci Med 2015;127:8-18.

34. Pollitt RA, Rose KM, Kaufman JS. Evaluating the evidence for models of life course socioeconomic factors and cardiovascular outcomes: a systematic review. BMC Public Health 2005;5:7.

35. Mackenbach JP, Bopp M, Deboosere P, et al. Determinants of the magnitude of socioeconomic inequalities in mortality: a study of 17 European countries. Health Place 2017;47:44-53.

36. Cavelaars AE, Kunst AE, Geurts JJ, et al. Educational differences in smoking: international comparison. BMJ 2000;320:1102-7.

37. Tabuchi T, Kondo N. Educational inequalities in smoking among Japanese adults aged 25-94 years: nationally representative sexand age-specific statistics. J Epidemiol 2017;27:186-92.

38. Pampel F, Legleye S, Goffette C, et al. Cohort changes in educational disparities in smoking: France, Germany and the United States. Soc Sci Med 2015;127:41-50.

39. Gregoraci G, van Lenthe FJ, Artnik B, et al. Contribution of smoking to socioeconomic inequalities in mortality: a study of 14 European countries, 1990-2004. Tob Control 2017;26:260-8. 